\title{
Optimization of Friction Stir Processing Parameters for Aluminum Alloy (AA6061-T6) Using Taguchi Method
}

\author{
Muna K. Abbass ${ }^{a *}$ and Noor Alhuda B. Sharhan ${ }^{a}$ \\ ${ }^{a}$ Dept. of Production Engineering and Metallurgy, University of Technology Baghdad-IRAQ.
}

\author{
A R T I CLE I NFO \\ Article history: \\ Received 28 December 2018 \\ Accepted 03 March 2019 \\ Keywords: \\ Aluminum alloy \\ Friction stir processing \\ Taguchi method \\ Mechanical properties
}

Received in revised form 25 February 2019

\begin{abstract}
A B S T R ACT
This work is devoted toward optimization of the parameters of the friction stir processing (FSP) which effect on tensile strength of aluminium alloy AA6061-T6 of 6mm thick plate by applying a certain number of tests utilizing the Taguchi method. Design of experiment (DOE) has been applied for the determination of the most important parameters influencing ultimate tensile strength. FSP was achieved under three different rotation speeds $(800,1000$ and 1250) rpm, different transverse speeds (16,25 and 32) $\mathrm{mm} \backslash \mathrm{min}$, and number passes(1,2 and 3 ) in the same direction and tool tilt angle was $2^{\circ}$ with using threaded cylindrical pin profile. The best FSP parameters were $1250 \mathrm{rpm}$ and $32 \mathrm{~mm} / \mathrm{min}$ and two passes. It was found that the higher hardness value was $75 \mathrm{HV}$ in stir zone center and then decreases toward the TMAZ, HAZ and the base metal.
\end{abstract}

(C) 2019 University of Al-Qadisiyah. All rights reserved.

\section{Introduction}

Aluminum alloys are important for many applications such as aerospace and automotive industries etc...., because of their light weight and high strength to weight ratio [1]. Because of the good properties of aluminum alloy 6061-T6, light weight, good strength, good erosion and corrosion properties, it is widely used in marine areas, cars and aircraft [2]. Homogenising and refining the grain structure of the alloy get better mechanical properties. Its ability be carried out via an assortment of processes such as high pressure-torsion (HPT), thermo mechanical treatment (TMT), accumulative roll-bonding (ARB), equal channel-angular process (ECAP), and so on. This process exhaustion time and complex [3]. Recently Friction Stir Processing (FSP), an innovative approach was developed for grain refinement and fabrication of surface composite materials. Its basic principles are the same as those of FSW. FSP is quite a promising method for the enhancement of metal properties [4]. This process causes high strain rates and intensive plastic deformation [5]. Through (FSP) a rotational tool pin sticks to the metal's surface that will be processed, then traversed along the paths. Heat will be produced via the friction between the rotating shoulder, the tool pin, and the surface of the metal. The metals' temperature doesn't reach its point of melting and only plastic-deformations appear in the region of processing. Recrystallization placed in the severely distorted metals, because of the homogeneous and refined structure of the grain in the stirred-area [6]. FSP has many benefits. FSP is a short route solid state process which has a single step processing which reaches homogeneity and micro-structural refinement. Also, the heat input through FSP come from plastic deformation and friction, and that refers to the fact that FSP is environment-friendly and energy-efficient approach with no radiation, noise and deleterious gas. FSP localizes modifications and controls of micro-structures in the near-surface layers of

* Corresponding author.

E-mail address: mukeab2014@yahoo.com (Muna K. Abbass) 
the processed components of the metal [7].The Taguchi method has been applied in a large scale to engineering analysis and is widely used in designing systems with high quality to investigate the effect of the FSP factors with using a small number of tests [8]. Kwon et al. [9] noticed that after applied FSP on 1050 aluminum alloy mechanical characteristics like hardness and tensile strength improved when decreasing the speed of the tool rotation. At 560rpm, those properties increased due to grain enhancement by nearly $37 \%$ and $46 \%$ respectively in comparison with the base alloy.Elangovan and Balasubramanian [10] studied the impact of the parameters of FSP (pin profile and speed of rotation) on AA2219 aluminum alloy has $6 \mathrm{~mm}$ thickness. Using five various tool pin-profiles (tapered cylindrical, straight cylindrical, threaded cylindrical, square and triangular) utilized three various tools rotational speed to manufacture weld. They have discovered that the square tool pin profile mechanically generates sound and metallurgically defects free welds in comparison with other tool pin profiles. Shafiei Zarghani et al. [11] used the FSP to create very small grained materials via strict plastic deformations. FSP has been performed for extruding 6082-T4 aluminum alloy for producing very small grained micro-structure with a grain of a size between $0.5 \mu \mathrm{m}$ and $3 \mu \mathrm{m}$. The FSPed aluminum alloy hardness considerably increases with the decrease in the speed of tool rotation. Elangovan and Balasubramanian [12] have proved that the impact of the FSP parameters (speed of rotation and pin profile) on AA6061 aluminum alloy. Using 5 various tool pin-profiles (threaded cylindrical, tapered cylindrical, straight cylindrical, square and triangular) utilized 3 different tools rotational speed to manufacture weld. They have discovered that the square pin profiled tool produced mechanical sounds and metallurgically defected free welds in comparison with other tool pin profiles. Magdy et al. [13] applied FSP on 6082-T6 aluminum alloy for improving the mechanical properties and modifying the micro-structure. At the fixed speed of rotation (850rpm) and 3 various traverse speeds $(90,140,224) \mathrm{mm} / \mathrm{min}$ was utilized for processing. Strength and hardness increased with the increase of traverse speed, increasing the number of passes resulted in lowering the ultimate tensile strength and softening.

The current study aims at obtaining the best parameters of FSP which are the speed of tool rotation, travel speed and a number of passes. The identification of the most effective parameters of friction stir processing is made by using L9 Taguchi orthogonal array. Furthermore, ANOVA is used to find out how much each parameter contributes to the process.

\section{Experimental work}

Aluminum alloy plate AA6061-T6 employed in this study. This plate was prepared into dimensions of $(150 \times 100 \times 6) \mathrm{mm}$ by using cutting machine. The chemical structure of this alloy has been performed with the use of spectro-meter analysis apparatus that has been presented in the "General Company for Examination and Rehabilitation Engineering ", as listed in Tables 1. The mechanical properties of the alloy listed in Table 2.

Table1: Chemical composition of the as-received AA6061-T6 alloy (weight \%)

\begin{tabular}{|c|c|c|c|c|c|c|c|c|c|c|c|}
\hline Element wt.\% & $\mathbf{S i}$ & $\mathbf{F e}$ & $\mathbf{C u}$ & Mn & Mg & $\mathrm{Cr}$ & $\mathbf{N i}$ & $\mathbf{Z n}$ & $\mathbf{T i}$ & Other & Al \\
\hline Nominal (value) [1] & $0.8 \max$ & $0.7 \max$ & $0.4 \max$ & $0.15 \max$ & $1.2 \max$ & $0.35 \max$ & $0.05 \max$ & $0.25 \max$ & $0.15 \max$ & $0.05 \max$ & Bal. \\
\hline Measured (value) & 0.636 & 0.586 & 0.258 & 0.105 & 0.916 & 0.183 & 0.0032 & 0.0357 & 0.051 & 0.0147 & Bal. \\
\hline
\end{tabular}

T6: Solution heat treatment and artificial aging.

Table 2: Mechanical properties of AA6061-T6 alloy

\begin{tabular}{lllll}
\hline Base Alloy AA6061-T6 & Yield strength YS (MPa) & Tensile strength TS (MPa) & Elongation \% & Hardness HV Kg/mm $^{2}$ \\
\hline Measured value & 160 & 314 & 28 & 58 \\
Standard value * & 276 & 310 & 12 & 95 \\
\hline
\end{tabular}

*Datasheet for ASM Aerospace Specification Metals Inc.

The FSP has been performed on a vertical milling machine (type: WMWHECKERT-Germany). The specimens are prepared and fixed in a specially designed and fabricated fixture and clamped firmly in order to ensure that the plates remain in their places and don't fly away because of the welding forces as shown in Fig. 1 and tool has been plunged into the chosen sheet area. A non-consumable cylindrical-shouldered and threaded pin made of high speed steel (HSS) with a shoulder diameter of $16 \mathrm{~mm}$ and $6 \mathrm{~mm}$ pin diameter of length $3.2 \mathrm{~mm}$ has been utilized as shown in Fig. 2 and tool tilt angle $2^{\circ}$.

\section{Orthogonal Array Selection}

The experimental design suggested by Taguchi covers the use of orthogonal arrays to arrange in order the parameters of FSP and the levels at which they must differ. In terms of the L9 orthogonal array suggested by Taguchi, three experiments were carried out on each set of parameters of the process. The three parameters which were used in this work were the speed of rotation (rpm), transverse speeds ( $\mathrm{mm} / \mathrm{min})$, and a number of passes (1,2 \& 3 ) in same direction. Table 3 shows the parameters and levels of the process. The tilt angle $\left(2^{\circ}\right)$ remains constant. A total of "nine experimental" runs were made, a set of levels was utilized for each control factor as shown in Table 3.

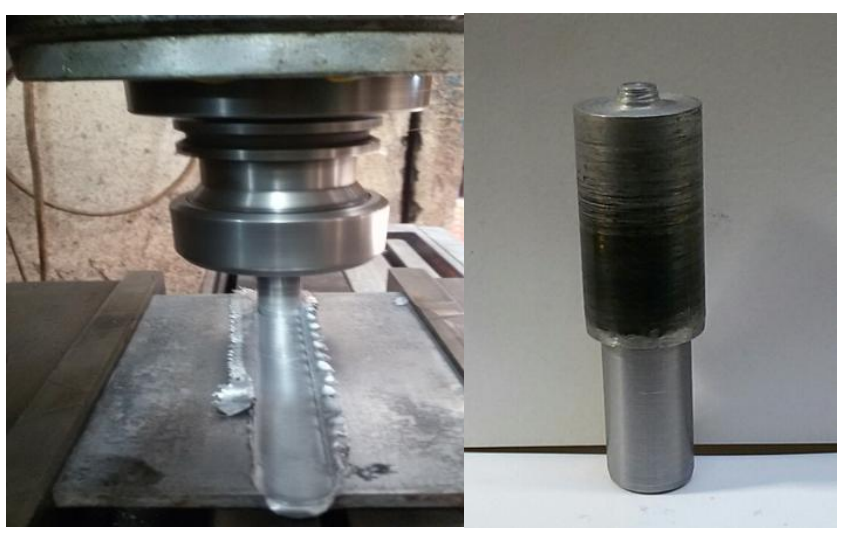

Figure 1: Sample after frictions stir processing
Figure 2 : The tool used in this work 
Table 3: Parameters and their levels of FSP

\begin{tabular}{llll}
\hline parameters & Level 1 & Level 2 & Level 3 \\
\hline Rotation speed RS (rpm) & 800 & 1000 & 1250 \\
Welding speed WS (mm\min) & 16 & 25 & 32 \\
Number of passes & 1 & 2 & 3 \\
\hline
\end{tabular}

Table 4: Experimental results of DOE Taguchi L9 Orthogonal array

\begin{tabular}{llll}
\hline Experiment Number & RS (rpm) & TS $(\mathbf{m m} / \mathbf{m i n})$ & No. of passes \\
\hline 1 & 800 & 16 & 1 \\
2 & 800 & 25 & 2 \\
3 & 800 & 32 & 3 \\
4 & 1000 & 16 & 2 \\
5 & 1000 & 25 & 3 \\
6 & 1000 & 32 & 1 \\
7 & 1250 & 16 & 3 \\
8 & 1250 & 25 & 1 \\
9 & 1250 & 32 & 2 \\
\hline
\end{tabular}

After friction stir processing tensile tests have been performed to estimate the tensile strength of FSP at all processing parameters. Tensile specimens were cut parallel to the FSP in the longitudinal direction by CNC milling machine type (C-TEK). Fig. 3 shows the dimensions with the geometry of the tensile sample according to the properties specified in the ASTM standard E8M- 011 for specimens of sub-size [14].

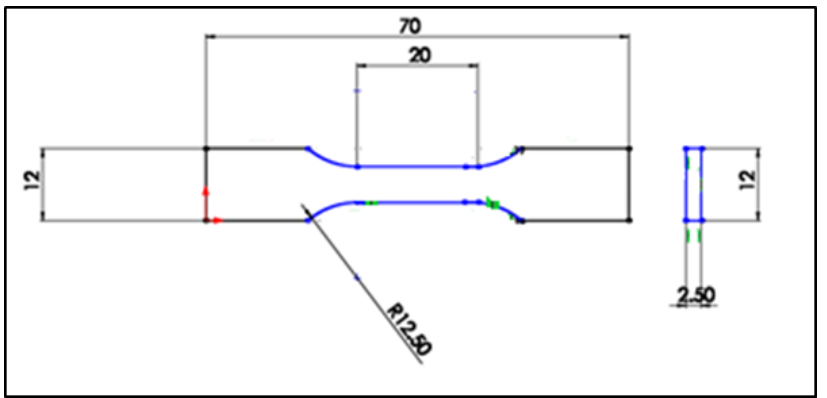

Figure 3: Sample of ASTM- E8M Sub-Size for Tensile Test, all dimensions in $\mathbf{m m}$

\section{Microstructure Examination and Microhardness Test}

An optical microscope was used to examine the specimens which were made from a cross-section of the FSP in sequences steps. The operation of wet grinding was made using water and emery paper of $\mathrm{SiC}$ in various grits of $320,500,600,800,1000$ and 1200 . The process of polishing was made on the samples using $0.5 \mu \mathrm{m}$ diamond paste and special cloth for polishing and lubricant. The process of etching was carried out on the specimens by utilizing etching solution Keller's reagent (composed of $95 \mathrm{ml} \mathrm{H}_{2} \mathrm{O}, 2.5 \mathrm{ml}$ $\mathrm{HNO}_{3}, 1.5 \mathrm{ml} \mathrm{HCL}, 1.0 \mathrm{ml} \mathrm{HF}$ ). They were washed and dried. Optical micro-scope is utilized to supply information concerning the microstructure of processing specimens. Digital micro-hardness tester type (Laryee, Mode HVS-1000) was utilized to conduct the Vickers hardness test. A $200 \mathrm{gm}$ load applied cross-section of SZ of the FSP direction, for 15 sec.

\section{Results and Discussion}

\subsection{Signal to Noise Ratio: (S\) Ratio}

Tensile strength is an important property taken into consideration in this study. For the estimation of the FSP parameters impact on tensile strength, values of means and $\mathrm{S} / \mathrm{N}$ ratio for every one of the direct factors (rotational speed of the tool, travel speed and a number of passes) have been considered. A suitable $\mathrm{S} / \mathrm{N}$ ratio has been selected utilizing previous knowledge, experience, and process understanding. Concerning this study, the $\mathrm{S} / \mathrm{N}$ ratio has been carefully chosen in terms of the standard of the higher is better, for the sake of maximizing the response. The method of Taguchi is utilized for determining the difference of the quality properties from the wanted value is achieved by using the $\mathrm{S} / \mathrm{N}$ ratio. In this study, the data of tensile strength have been analyzed to decide the influence of FSP parameters. Table 5 depicts the 3 levels of parameters of the process as "per L9 orthogonal array", the means of tensile strength and the matching S/N ratio. Analyzing the mean for every experiment will result in better parameter combination level so that tensile strength at a high level is made certain in terms of experimental data. The plots as in Figures (4 and 5) may be utilized for identifying the highest level of process parameter conformity to the biggest $\mathrm{S} / \mathrm{N}$ ratio and tensile strength respectively. The tensile strength is assessed to be the highest with speed of rotation of $1250 \mathrm{rpm}$ and travel speed $32 \mathrm{~mm} / \mathrm{min}$ and two passes which is optimal from the plots obtained.

Table 5: Tensile strength and S/N Ratio for experiments.

\begin{tabular}{llllll}
\hline $\begin{array}{l}\text { Experiment } \\
\text { number }\end{array}$ & $\begin{array}{l}\text { RS } \\
(\mathbf{r p m})\end{array}$ & $\begin{array}{l}\text { TS } \\
(\mathbf{m m} \backslash \mathbf{m i n})\end{array}$ & $\begin{array}{l}\text { No. of } \\
\text { passes }\end{array}$ & $\begin{array}{l}\text { Mean } \\
\text { tensile } \\
\text { strength } \\
\mathbf{M P a}\end{array}$ & $\begin{array}{l}\text { S\N } \\
\text { ratio }\end{array}$ \\
\hline 1 & & & 1 & 162 & 44.19 \\
2 & 800 & 16 & 2 & 158 & 43.97 \\
3 & 800 & 25 & 3 & 152 & 43.63 \\
4 & 800 & 32 & 2 & 159 & 44.02 \\
5 & 1000 & 16 & 3 & 138 & 42.79 \\
6 & 1000 & 25 & 1 & 165 & 44.34 \\
7 & 1000 & 32 & 3 & 160 & 44.08 \\
8 & 1250 & 16 & 1 & 170 & 44.60 \\
9 & 1250 & 25 & 2 & 215 & 46.64 \\
\hline
\end{tabular}

\subsection{Analysis of Variance (Anova)}

This test is applied for studying the significance regarding the FSP's parameters affecting the tensile strength related to processing with FSP. To determine which one of the processes significantly impact the tensile strength, the F-test which is termed after Fisher might be applied. Generally, the process parameter's difference holds a considerable impact on the quality characteristics related to the tensile strength of the processing, in the case when $\mathrm{F}$ is considered high. The ANOVA test results indicate that the process's parameters are very important factors which influence the tensile strength with FSP in the order of a number of passes, travel and rotation speeds. From Table 6 it was shown that the ANOVA of tensile result display that the rotation speed is considered as the utmost effective parameter having a percentage of $38.68 \%$ after that comes the number of passes $31.9 \%$ and travel speed $22.55 \%$. 


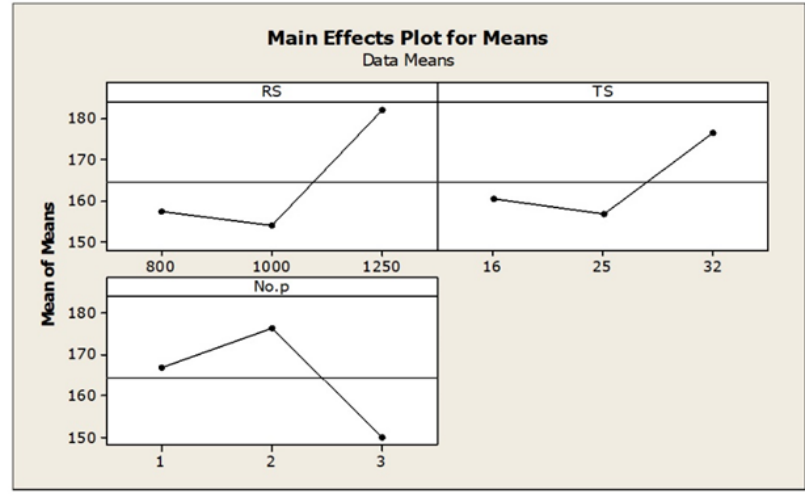

Figure 4 :Main effect plot for $\mathrm{S} / \mathrm{N}$ ratios

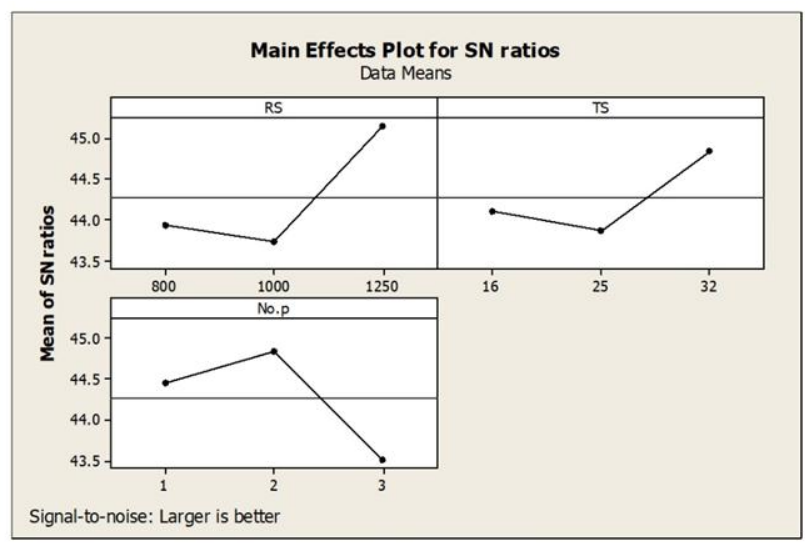

Figure 5: Main effect plot for mean tensile strength

Table 6: ANOVA for FSP parameters

\begin{tabular}{lllllll}
\hline Parameters & DF & $\begin{array}{l}\text { Seq } \\
\text { SS }\end{array}$ & $\begin{array}{l}\text { Adj } \\
\text { SS }\end{array}$ & $\begin{array}{l}\text { Adj } \\
\text { MS }\end{array}$ & F & PA\% \\
\hline $\begin{array}{l}\text { Rotation speed } \\
\text { RS (rpm) }\end{array}$ & 2 & 1368.7 & 1368.7 & 684.3 & 5.64 & 38.68 \\
$\begin{array}{l}\text { Travel speed } \\
\text { TS(mm/min) }\end{array}$ & 2 & 798.0 & 798.0 & 399.0 & 3.29 & 22.55 \\
$\begin{array}{l}\text { Number of } \\
\text { passes }\end{array}$ & 2 & 1128.7 & 1128.7 & 564.3 & 4.65 & 31.9 \\
Error & 2 & 242.7 & 242.7 & 121.3 & - & 6.87 \\
Total & - & - & - & - & - & $100 \%$ \\
\hline
\end{tabular}

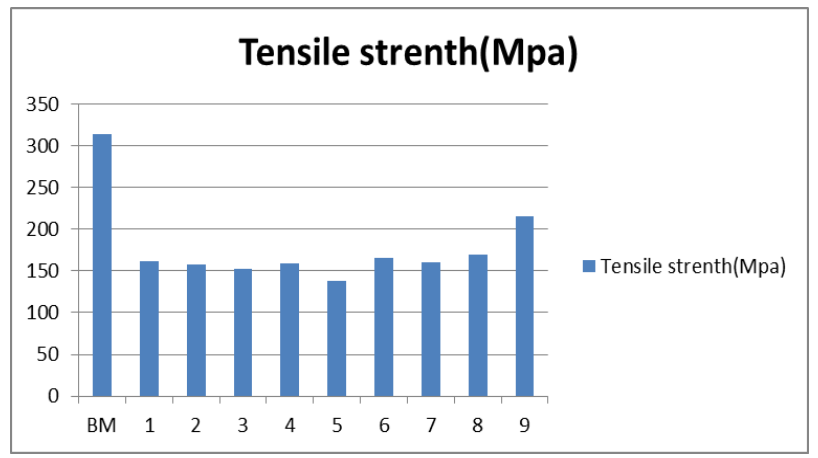

Figure 6: The tensile strength of base alloy AA6061-T6 and FSPed samples

\subsection{TENSILE TEST RESULTS}

The tensile results indicated the fact that the tensile strength regarding the base alloy has been greater than that of all friction stir processing tested as shown in Fig. 6. According to the test results, the increment in the travel and rotations speeds will lead to an increment in the tensile strength.

At a tool rotation speed of (1250 rpm), the tensile strength had its highest value. In comparison to un processing alloy, it has been discovered that the tensile strength will decrease with increased tool rotation speed, the is because of the extra heat that is generated in the stir zone because of the high rotational speed for the tool, and thus increasing stirring influence which is related to the pin, however it could create extra explosion or flash of metal flow outside causing imperfections in stir-zone. Similarly, elevated heat inputs will cause an increase in peak temperature and triggers graingrowth, that will cause a reduction in the tensile strength.

At FSP speeds of $(16 \mathrm{~mm} / \mathrm{min})$ and $(25 \mathrm{~mm} \backslash \mathrm{min})$, it has been spotted that the tensile strength has been lesser than of speed (32 $\mathrm{mm} / \mathrm{min})$, this is considered as the result of the elevated frictional heat and dissipation most of the heat created regardless of tool rotations speed as well as the number of passes. The minimum rotational speed leads to decrease the FSP's tensile strength because of the higher heat input in processing samples, whereas the maximum rotation speed causes an increase in tensile strength which will result in short exposure time to frictional heating.

The FSP at two passes has higher tensile strength than that of one or three passes. This is because the FSP at 2 passes created a pronounced effect in refining the stir zone microstructure and the break-up of inter metallic compound. The best value of tensile strength of FSP (215MPa) was achieved at (1250rpm) rotating speed $(32 \mathrm{~mm} / \mathrm{min})$ rotation speed and two passes. The acquired results are consistent with the results obtained by the researcher Magdy et al. [13].

\subsection{Microhardness Results}

Microhardness distribution along FSP cross section is displayed in Fig. 7, Vickers- micro-hardness apportionment on cross section vertical to the tool traverse direction regarding the FSP sample formed at a tool rotational speed of $1250 \mathrm{rpm}$ and travel speed $32 \mathrm{~mm} / \mathrm{min}$ with two passes. The stirzone showed a higher hardness than the unaffected zone. The maximum hardness was $75 \mathrm{HV}$ in center of stir zone. This is due to refining grain and dynamic recrystalline stir zone and presence of precipitates $2^{\text {nd }}$ phase particles of $\mathrm{Al}_{3} \mathrm{Mg}_{2}$ phase in $\alpha$-Al. Several researchers $[15,16]$ proved these outcomes in their studies of FSW welding aluminum alloys.

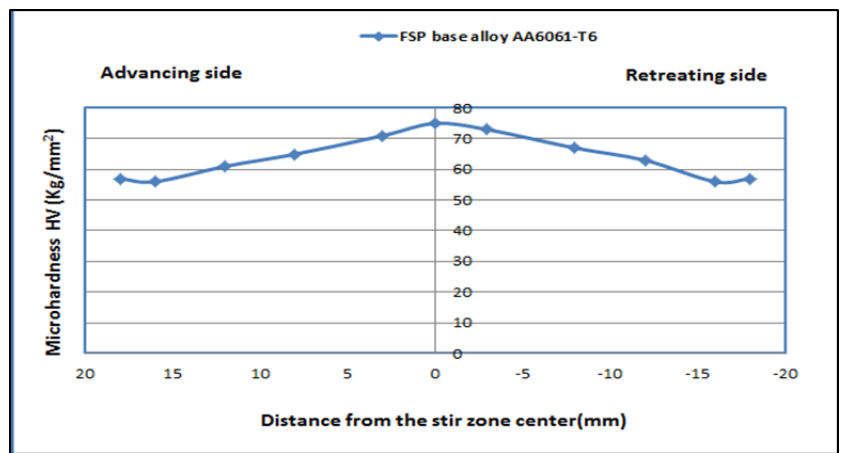

Figure 7 : Microhardness distribution across the transverse cross section of FSP for base metal at rotation speed $1250 \mathrm{rpm}$, travel speed 32 and two passes 


\subsection{Microstructure Results}

Fig. 8 (a,b,c \&d) shows the microstructural characterization of a cross section of friction stir processing at best parameters $(1250 \mathrm{rpm}, 32 \mathrm{~mm} / \mathrm{min}$ and 2 passes). It is seen that the FSP sample has four distinct regions: stir zone (SZ) is the region that is thermo-mechanically processed zone where the grain size is very fine and equaxed grains or homogenized structure (Fig. 8a), friction stir processed zone (FSP zone) (Fig. 8c), the thermo mechanically affected-zone (TMAZ) in which the grain is elongated due to the fact that it has been deformed in a thermo- mechanical way with observation of union rings (Fig. 8b), heat affected-zone (HAZ) which is considered to have the same grain structure of base metal (BM) and the base metal or AA6061-T6 alloy (unaffected metal ) considered as the region which is not influenced through the FSP process. This microstructure contains very fine precipitates $2^{\text {nd }}$ phase particles of $\mathrm{Al}_{3} \mathrm{Mg}_{2}$ phase distributed uniformly in $\alpha$-Al.( Fig. 8d).
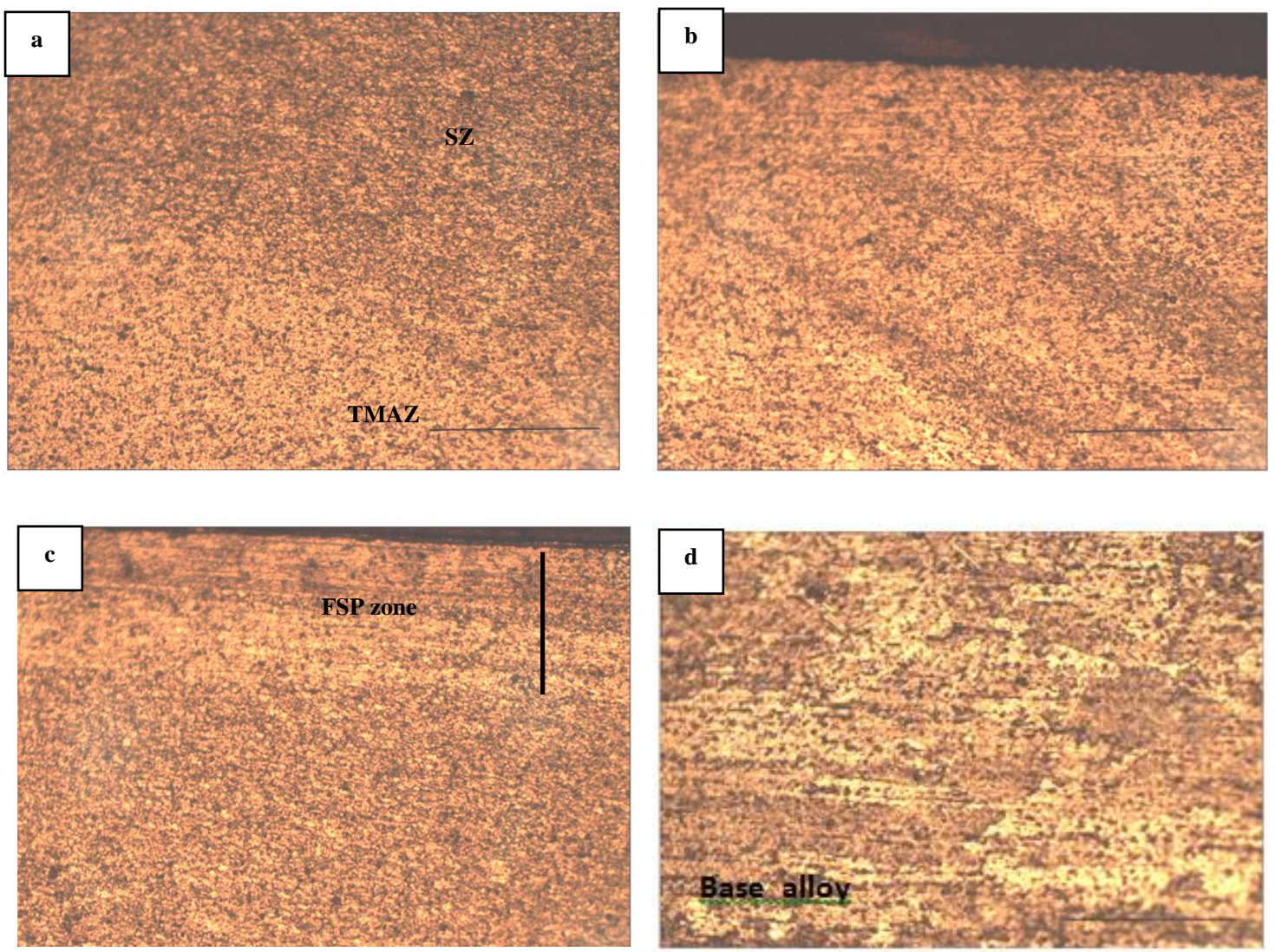

- It was found that optimum or best friction stir processing (FSP) parameters were $1250 \mathrm{rpm}$ of rotation speed, $32 \mathrm{~mm} / \mathrm{min}$ of travel speed

- Tensile strength of FSP ed sample increases as the rotation speed and travel speed increase.

- It has been indicated that the stir zone of FSP exhibited microhardness higher than TMAZ and HAZ because of grain refinement and existence of precipitates $(\mathrm{A} 13 \mathrm{Mg} 2)$ distributed in the aluminum matrix.

- It was shown from ANOVA analysis of tensile strength that the rotation speed has contribution percentage (38.68\%) which is the most effective parameter followed by a number of passes was $31.9 \%$ and then travel speed was $22.55 \%$.

\section{6. conclusions} and two passes for a number of passes.

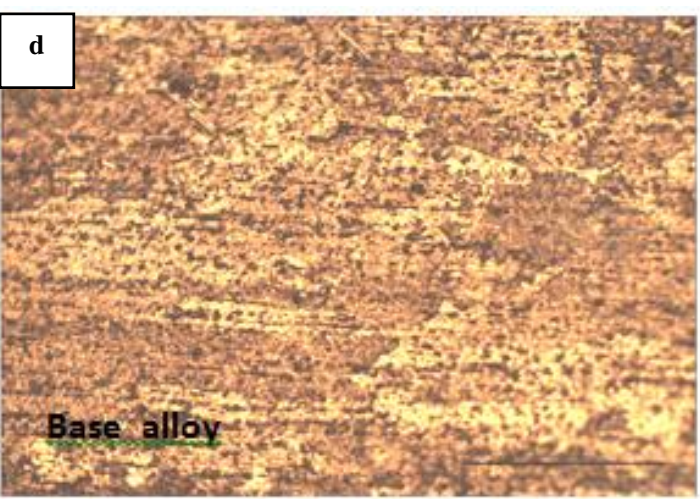

Figure 8: Microstructure of friction stir processed ( FSP ) sample at optimum conditions $1250 \mathrm{rpm}, 32 \mathrm{~mm} / \mathrm{min}$ and 2 pass in same direction at 100x. (a) SZ and TMAZ ，(b) Union rings in TMAZ , (c) FSP zone , (d) Base alloy AA6061-T6.

\section{REFERENCES}

[1] C. Saravanan, K. Subramanian, V.A. Krishnan, R.S. Narayanan, Effect of particulate reinforced aluminium metal matrix composite-a review, Mechanics and Mechanical Engineering, 19(1) (2015) 23-30.

[2] V. Kishan, A. Devaraju, K.P. Lakshmi, Influence of volume percentage of NanoTiB2 particles on tribological \& mechanical behaviour of 6061-T6 Al alloy nano-surface composite layer prepared via friction stir process,
Defence Technology, 13(1) (2017) 16-21.

[3] G. Venkateswarlu, M.J. Davidson, P. Sammaiah, Effect of Friction Stir Processing Process Parameters on the Mechanical Properties of AZ31B Mg Alloy, Manufacturing and Industrial Engineering, 13(1-2) (2014).

[4] N.M. Daniolos, D.I. Pantelis, P.I. Sarafoglou, AA7075/A12O3 Surface Composite Materials Fabrication Using Friction Stir Processing, in: 2nd International Conference of Engineering Against Fracture (ICEAF II), Mykonos, GREECE, 2011.

[5] D. Deepak, R.S. Sidhu, V. Gupta, Preparation of 5083 Al-SiC surface composite by friction stir processing and its mechanical characterization, 
International Journal of Mechanical Engineering, 3(1) (2013) 1-11.

[6] Q. Liu, L. Ke, F. Liu, C. Huang, L. Xing, Microstructure and mechanical property of multi-walled carbon nanotubes reinforced aluminum matrix composites fabricated by friction stir processing, Materials \& Design, 45 (2013) 343-348.

[7] Z. Ma, Friction stir processing technology: a review, Metallurgical and materials Transactions A, 39(3) (2008) 642-658.

[8] S.K. Karna, D.R.V. Singh, D.R. Sahai, Application of Taguchi method in indian industry, International Journal of Emerging Technology and Advanced Engineering, 2(11) (2012) 387-391.

[9] Y. Kwon, I. Shigematsu, N. Saito, Mechanical properties of fine-grained aluminum alloy produced by friction stir process, Scripta Materialia, 49(8) (2003) 785-789.

[10] K. Elangovan, V. Balasubramanian, Influences of pin profile and rotational speed of the tool on the formation of friction stir processing zone in AA2219 aluminium alloy, Materials Science and Engineering: A, 459(1-2) (2007) 718.

[11] A. Shafiei Zarghani, S. Kashani Bozorg, A. Zarei-Hanzaki, Ultrafine grained 6082 aluminum alloy fabricated by friction stir processing, International Journal of Modern Physics B, 22(18n19) (2008) 2874-2878.

[12] K. Elangovan, V. Balasubramanian, Influences of tool pin profile and tool shoulder diameter on the formation of friction stir processing zone in
AA6061 aluminium alloy, Materials \& design, 29(2) (2008) 362-373.

[13] M.M. El-Rayes, E.A. El-Danaf, The influence of multi-pass friction stir processing on the microstructural and mechanical properties of Aluminum Alloy 6082, Journal of Materials Processing Technology, 212(5) (2012) 1157-1168.

[14] N. Yuvaraj, S. Aravindan, Fabrication of Al5083/B4C surface composite by friction stir processing and its tribological characterization, Journal of materials research and technology, 4(4) (2015) 398-410.

[15] M.K. Abbass, H.H. Abd, A Comparison Study of Mechanical Properties between Friction StirWelding and TIG Welded Joints of Aluminum Alloy (Al 6061-T6), Engineering and Technology Journal, 31(14 Part (A) Engineering) (2013) 2701-2715.

[16] M.K. Abbass, K.M. Raheef, EFFECT OF WE LDING PARAMETERS ON MECHANICAL PROPERTIES OF FRICTION STIR LAP WELDED JOINTS FOR SIMILAR ALUMINUM ALLOYS (AA1100-H112 \& AA6061-T6), Journal of Engineering and Sustainable Development, 22(2) (2018) 60-71.

[17] W. Rashid, EFFECT OF SOME FACTORS IN THE FRICTION STIR WELDING ON TENSILE STRENGTH OF AL-Zn-Mg ALLOY, AlQadisiyah Journal For Engineering Sciences, 8(3) (2015) 398-409. 